\title{
Erythema marginatum: an uncommon presentation of acute rheumatic fever in a Nigerian adolescent girl-a case report
}

\author{
Barakat Adeola Animasahun ${ }^{1 *}$, Faith O. Lawani ${ }^{2}$ and Moriam Omolola Lamina²
}

\begin{abstract}
Background: Erythema marginatum is an uncommon presentation in children with acute rheumatic fever and it is one of the major criteria needed to make a diagnosis. It is seen in less than $10 \%$ of cases. It is also reported to be difficult to detect in black-skinned children. This is the first and only patient to present with the above since the inception of the unit about 14 years ago and also the first to be reported in Nigeria as far as the authors are aware, after a careful literature search; hence, we report this case based on the rarity of this symptom of acute rheumatic fever.

Case presentation: This is a case report of O.E, a 12-year-old Nigerian girl who presented with features of acute rheumatic fever, and these features included the rare manifestation of erythema marginatum. She presented with generalized skin eruptions on the trunk and extremities, sparing the face, migratory polyarthritis, features of congestive heart failure and high grade continuous fever. The skin lesions consisted of papules, patches, plaques and polycycles with a reticular pattern having serpiginous and raised borders. Diagnostic investigations revealed elevated erythrocyte sedimentation rate of $83 \mathrm{~mm} / \mathrm{h}$, anti-streptolysin O titer of 2020IU/L and echocardiography which showed thickened mitral valves with grade II mitral regurgitation and a mild pulmonary artery hypertension. The patient was treated with anti-inflammatory and anti-failure drugs and commenced secondary prophylaxis with benzathine penicillin. Skin eruptions resolved within 3 weeks of management and are currently on follow up.

Conclusions: We present the above to increase awareness on the possibility of acute rheumatic fever presenting with erythema marginatum in our region, to encourage early diagnosis of acute rheumatic fever to reduce morbidity and mortality from its sequel, rheumatic heart disease.
\end{abstract}

Keywords: Erythema marginatum, Acute rheumatic fever, Adolescent, Nigerian girl

\section{Background}

Acute rheumatic fever (ARF) is an inflammatory disease involving the heart, skin, joints and brain that results from an autoimmune response to pharyngitis caused by Group A beta-haemolytic Streptococcus (GAS) [1, 2]. The development of ARF occurs approximately 2 to 4 weeks after an untreated or inadequately treated GAS pharyngitis [3]

\footnotetext{
* Correspondence: deoladebo@yahoo.com

'Department of Paediatrics and Child Health, Lagos State University College of Medicine, Ikeja, Lagos, Nigeria

Full list of author information is available at the end of the article
}

Initial and or recurrent episodes of ARF can lead to rheumatic heart disease which is the commonest cause of acquired heart disease in developing countries [1, 4]. Cases of ARF are rarely seen either due to misdiagnosis or inadequate diagnosis and late presentation as most patients usually present as rheumatic heart disease which is a complication $[4,5]$. Acute rheumatic fever remains highly prevalent in developing countries where factors like overcrowding, poverty, malnutrition and poor access to health care are identifiable risk factors [4]. It is commonly seen in children between 5 and 15 years of age, though initial cases of ARF can affect

\section{Springer Open}

(- The Author(s). 2021 Open Access This article is licensed under a Creative Commons Attribution 4.0 International License, which permits use, sharing, adaptation, distribution and reproduction in any medium or format, as long as you give appropriate credit to the original author(s) and the source, provide a link to the Creative Commons licence, and indicate if changes were made. The images or other third party material in this article are included in the article's Creative Commons licence, unless indicated otherwise in a credit line to the material. If material is not included in the article's Creative Commons licence and your intended use is not permitted by statutory regulation or exceeds the permitted use, you will need to obtain permission directly from the copyright holder. To view a copy of this licence, visit http://creativecommons.org/licenses/by/4.0/. 
children younger than 5 years and occur evenly among males and females $[6,7]$.

The pathogenesis and immune mechanisms linking ARF to GAS pharyngitis are still not completely understood [8]. However, it has been postulated that a combined humoral and cellular immune response occurs to the bacterium's antigen ( $M$ protein) which cross reacts with human tissue such as the joints, skin, heart and brain through molecular mimicry [9].The clinical manifestations of ARF are part of the 2015 revised Jones criteria $[9,10]$ which is used in making a diagnosis of ARF.

Erythema marginatum is a rare manifestation of ARF and is seen in less than $10 \%$ of cases $[11,12]$. It is described as a non-pruritic, macular, evanescent, erythematous rash with pale centres and serpiginous borders occurring on the trunk and extremities while sparing the face [13]. It is difficult to detect erythema marginatum in black-skinned people and to the best of the authors' knowledge has been rarely reported in African children. Hence, we report a case of ARF presenting with erythema marginatum in a 12-year-old girl in view of the rarity and to increase awareness of ARF among healthcare practitioners.

\section{Case presentation}

A 12-year-old girl who presented with a 4-week history of high grade, continuous fever, only temporarily relieved by use of oral analgesic (paracetamol), a 3-week history of migratory joint pains and swelling involving the elbow, knee and ankle joints with generalized skin eruptions of 2 weeks duration prior to presentation involving the trunk and extremities but sparing the face, non-itchy, accentuated after taking a warm bath and a 1week history of difficulty with breathing, easy fatigueability, orthopnea and bilateral leg swelling which necessitated referral from the referring hospital.

There was no preceding history of a sore throat or features of an upper respiratory tract infection few weeks to onset of symptoms. Neither was there a prior history of similar complaints in the past nor a history of abdominal or facial swelling and oliguria. She was in junior secondary school and resided in the dormitory (boarding school). She received treatment at two different private hospitals where she was commenced on analgesics and antibiotics. She was transfused with blood at the second private hospital on account of packed cell volume of $25 \%$ and referred to our hospital for further management.

Ante-natal, birth and post-natal periods were uneventful. She achieved motor (gross and fine) and speech milestones at the appropriate age. Her past results in school showed good academic performance. She had received all vaccines according to the National Program on Immunization schedule. She was the third of four children in a monogamous family.

On examination at presentation, she was in respiratory distress (flaring alae nasi, intercostal and subcostal recessions), febrile with a temperature of $38.5^{\circ} \mathrm{C}$, with generalized circular and coalescing skin eruptions on the trunk, back and extremities sparing the face with pale centres and serpiginous borders (Figs. 1, 2, and 3), mildly pale, acyanosed in room air with pedal oedema up to the mid-shin. She was tachypnoeic with a respiratory rate of 68 cycles/min, with basal coarse crepitation bilaterally on auscultation of the lungs. She had tachycardia with a pulse rate of 135 beats/min which was regular, normal volume and synchronous with other peripheral pulses. She had normal blood pressure for age. The precordium was hyperactive with displaced and diffuse apex beat located at the 6th left intercostal space anterior axillary line and a first, second and third heart sounds with a grade 3 pan-systolic murmur loudest at the apex and radiating to the left axilla. Abdominal examination revealed a soft, smooth and tender hepatomegaly with a palpable edge $6 \mathrm{~cm}$ below the right costal margin. Musculoskeletal system examination revealed swollen left elbow, left knee and right ankle joints which were markedly tender.

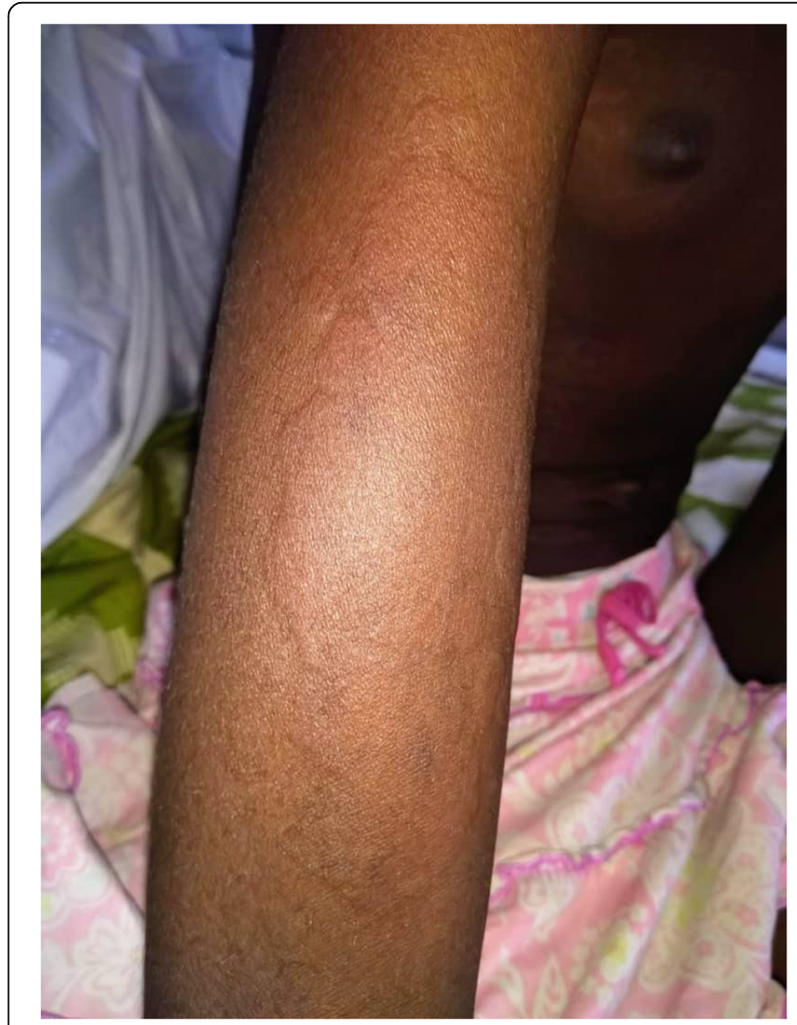

Fig. 1 Skin eruptions on the extensor surface of the right arm showing plaques and coalesced lesions with raised border 


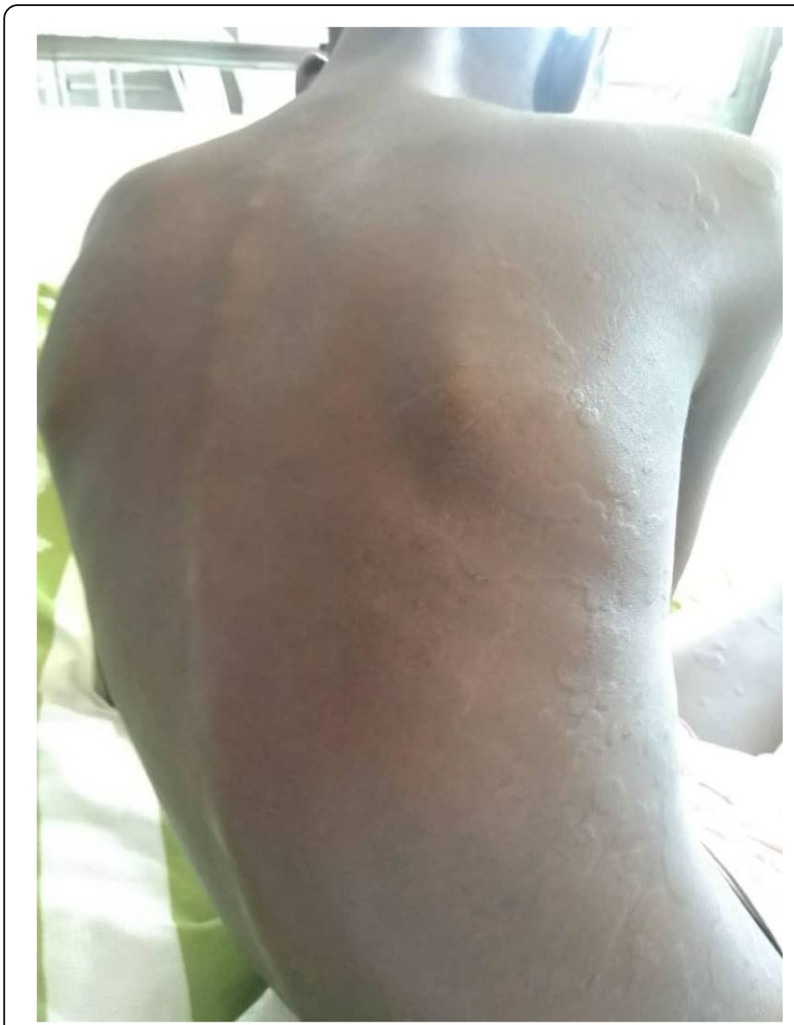

Fig. 2 Skin eruptions on the back showing papules, plaques, patches and polycyclic lesions with a reticular pattern having serpiginous and raised borders

An initial diagnosis of congestive cardiac failure secondary to carditis in a child with acute rheumatic fever was made. Chest radiograph showed cardiomegaly with CTR of $62 \%$. Electrocardiography showed sinus tachycardia, right atrial enlargement and right axis deviation. Echocardiography (Fig. 4) revealed dilated right atrium, dilated LV and slightly thickened mitral valve with no movement restriction. There was prolapse of the anterior leaflet of the mitral valve and grade 3 mitral regurgitation with ejection fraction of $70 \%$. Right sided function was normal but there was mild tricuspid regurgitation with a pressure gradient of $25 \mathrm{mmHg}$ in keeping with a mild pulmonary artery hypertension. The full blood count study showed features of iron deficiency anaemia with packed cell volume of $28 \%$, thrombocytosis with platelet count of $669,000 / \mathrm{mm}^{3}$, reduced mean corpuscular volume (MCV) of $69 \mathrm{fL}$ and mean corpuscular haemoglobin $(\mathrm{MCH})$ of $22.5 \mathrm{pg}$ with increased red cell distribution width (RDW) of $19.2 \%$. The full blood count also revealed neutrophilia with left shift and presence of toxic granulations. Erythrocyte sedimentation was elevated with a value of $83 \mathrm{~mm} / \mathrm{h}$. Antistreptolysin $\mathrm{O}$ titre was also elevated at $2020 \mathrm{IU} / \mathrm{ml}$; throat swab microscopy, culture and sensitivity were negative for streptococcus while serum electrolytes, urea and creatinine were within normal limits.

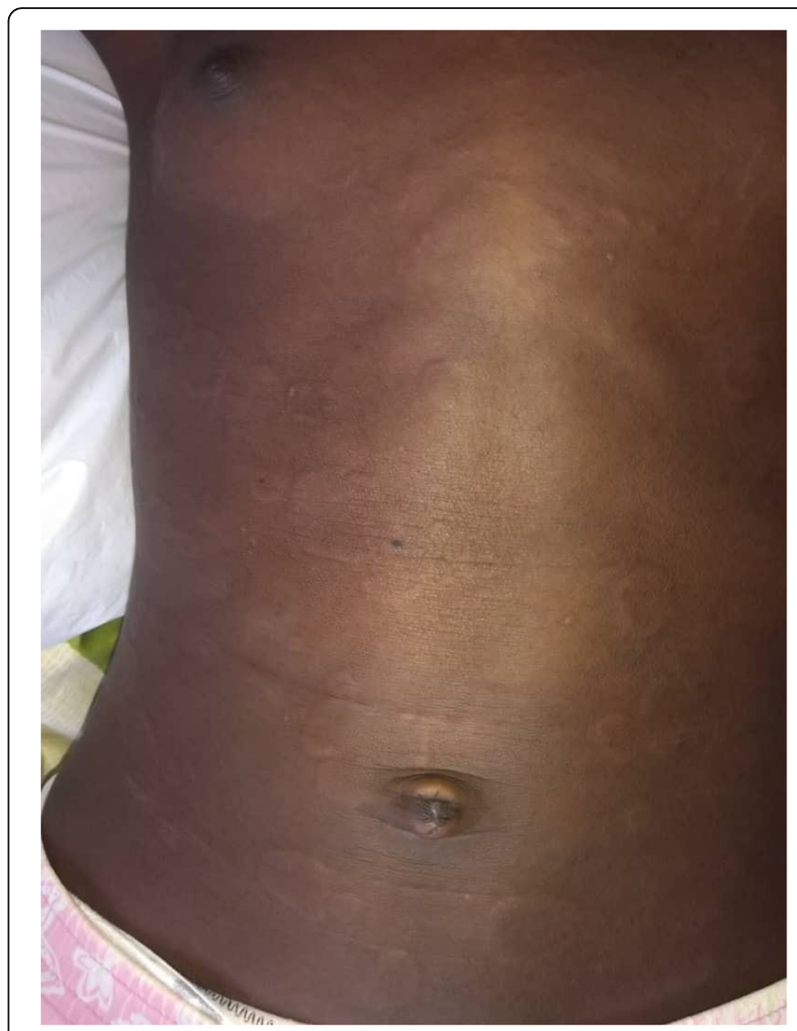

Fig. 3 Skin eruptions on the trunk showing macules, plaques and patches with pale centres and raised borders

A diagnosis of acute rheumatic fever was made using the Jones criteria. She had three major criteria (erythema marginatum, polyarthritis, carditis) and two minor criteria (fever, elevated erythrocyte sedimentation rate) with evidence of recent streptococcal infection. She was

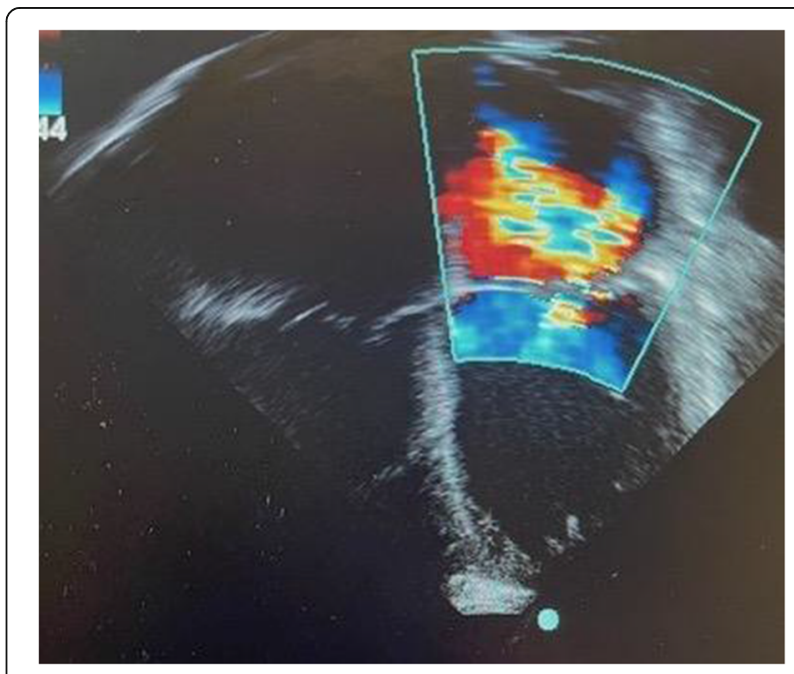

Fig. 4 Echocardiography showing dilated right atrium, dilated LV and slightly thickened mitral valve with no movement restriction. There was prolapse of the anterior leaflet of the mitral valve and grade 3 mitral regurgitation 
admitted, commenced on intranasal oxygen and nursed in cardiac position with anti-failure (intravenous frusemide, oral enalapril, anti-inflammatory drugs (Aspirin) and antibiotics and low salt diet (second-generation cephalosporin). Secondary prophylaxis was commenced with intramuscular benzathine penicillin 600,000 IU every 3 weeks after a test dose. Remarkable clinical improvement was made; joint pains and swelling and symptoms of congestive cardiac failure resolved within 1 week while the fever and skin eruptions resolved within the second and third week of admission respectively. She was discharged after 4 weeks on admission. She is being followed up regularly in the cardiology clinic and to continue with three weekly benzathine penicillin prophylaxis.

\section{Discussion}

Erythematous skin lesions have been associated with rheumatic fever as early as 1922 by physicians (Lehndorff and Leiner) who described that the lesions begin as a solid erythema which may be slightly raised and the erythema extends outwards while the skin in centre returns back to normal, hence the name erythema marginatum. Other physicians, Perry (1937) and Kiel (1938), described similar lesions [13].

Erythema marginatum is rarely seen in patients with acute rheumatic fever occurring in only about less than $10 \%$ of cases as against polyarthritis (present in $80 \%$ of patients) and carditis (seen in about $50 \%$ of patients) [11, $12,14]$. It is difficult to see in dark-skinned people and is described as a macular, evanescent rash that may become patches or plaques or merge to form a polycyclic or reticular pattern. They are non-painful, non-pruritic, pink or bright red in colour, blanch under pressure, with pale centres and a serpiginous or raised border. The most frequently involved sites are the trunk, especially the abdomen and occasionally the upper and lower extremities while sparing the face. They are accentuated by warm bath and are strongly associated with the presence of carditis in patients with acute rheumatic fever. It may however persist or recur for months or even years, continuing after other manifestations of the disease have subsided $[4,15]$.

Following an untreated or inadequately treated Group A Streptococcus pharyngitis, in the presence of environmental factors (overcrowding, poverty, malnutrition) and genetic susceptibility (polygenetic with suspected genes like HLA-DR7 and other class II MHC alleles), there is activation of the innate immune system which introduces the Group A Streptococcus antigens to T and B cells. This leads to activation of $\mathrm{CD} 4+\mathrm{T}$ cells which further activates $\mathrm{B}$ cells to produce IgG and IgM antibodies. The CD4+ T cells identify the M5 protein peptides of the bacteria and result in the generation of inflammatory cytokines such as
TNF-alpha, IFN-gamma, IL-10 and IL-4. This immune complex formed is deposited on host tissues including the skin (molecular mimicry) resulting in tissue inflammation and injury. This rare skin manifestation, erythema marginatum, might be due to antibodies against group A carbohydrate cross-reacting with keratin, laminin, tropomyosin and $\mathrm{N}$-acetylglucosamine $[3,4,16]$.

No laboratory test is needed for the diagnosis of erythema marginatum; however, skin biopsy can be done and this shows a perivascular infiltration of lymphocytes, eosinophils and predominantly neutrophils in the papillary dermis and upper portion of the reticular dermis; sometimes, leukocytoclasia may be associated but without true vasculitis [17]. There is also no specific treatment for erythema marginatum as lesions resolve spontaneously and it is not influenced by antiinflammatory therapy $[4,13]$.

A study by Joyce B. Burke [13] in 14 children with acute rheumatic fever who presented with erythema marginatum and other major features of acute rheumatic fever revealed that erythema marginatum appeared at any time during or after an attack of acute rheumatic fever, varied in duration from 2 days to 2 and a half years and was uninfluenced by treatment with salicylates or steroids.

\section{Conclusions}

We documented a case of ARF in an African child presenting with erythema marginatum. Erythema marginatum is a rare presentation of ARF and even more so in the black population. Cases of reported ARF itself is rare in developing countries despite being a disease of lowincome countries due to problems of overcrowding, poverty, poor health seeking behaviours and poor access to health care. The description of the rash is characteristic of EM. There is no specific treatment for EM as it can take days to years to resolve even after treatment of the other components of ARF. Physicians should be careful not to overlook this rare but useful clinical manifestation of ARF particularly in African children.

\section{Abbreviations \\ ARF: Acute rheumatic fever; CTR: Cardiothoracic ratio; EM: Erythema marginatum; MCV: Mean corpuscular volume; MCH: Mean corpuscular} haemoglobin; RDW: Red cell distribution width

\section{Acknowledgements}

We gratefully acknowledge the patient, parents and all the healthcare personnel involved in her care.

\section{Authors' contributions}

AA was the project leader and participated in the design, supervision and manuscript writing. FL and ML also participated in the manuscript writing. All the authors participated in the conceptualization, design, and critical review of the manuscript and read and approved the final manuscript.

Funding

The write-up was sponsored by all the authors. 
Availability of data and materials

Data on the case report are available and have been submitted in the report.

\section{Declarations}

Ethics approval and consent to participate

Approval obtained from the Lagos State University Teaching Hospital Ethics Committee but the need for approval was waived.

\section{Consent for publication}

Written informed consent to publish this information was obtained from the parent of the study participant.

\section{Competing interests}

No competing interests among the authors.

\section{Author details}

'Department of Paediatrics and Child Health, Lagos State University College of Medicine, Ikeja, Lagos, Nigeria. ${ }^{2}$ Department of Paediatrics, Lagos State University Teaching Hospital, Ikeja, Lagos, Nigeria.

Received: 30 March 2021 Accepted: 24 August 2021

Published online: 04 October 2021

\section{References}

1. Carapetis JR, Beaton A, Cunningham MW, Guilherme L et al (2018) Acute rheumatic fever and rheumatic heart disease. Nat Rev Dis Prim 2:1-57

2. Liang-choo H, Rajaram N (2016) A review of acute rheumatic fever and rheumatic heart disease research in Malaysia. Med J Malaysia 71:79-86

3. Cunningham MW (2000) Pathogenesis of group A streptococcal infections. Clin Microbiol Rev 13(3):470-511. https://doi.org/10.1128/CMR.13.3.470

4. WHO (2004) Rheumatic fever and rheumatic heart disease. In: Report of a WHO expert Consultation. WHO, Geneva, pp 1-130

5. Animasahun BA, Madise-Wobo DA, Itiola AY et al (2018) The burden of acute rheumatic fever among children in Lagos: how are we fairing? Pan Afri Med J 29:1-10

6. Abdin ZH. Eissa A (1965) Rheumatic fever and rheumatic heart disease in children below the age of 5 years In The Tropics. Ann Rheum Dis 24(4):389391. https://doi.org/10.1136/ard.24.4.389

7. Chockalingam A, Prabhakar D, Dorairajan S, Priya C, Gnanavelu G, Venkatesan S (2004) Rheumatic heart disease occurrence, patterns and clinical correlates in children aged less than five years. J Hear Valve Dis 13:11-14

8. Cilliers AM (2006) Rheumatic fever and its management. Benha Med J 333(7579):1153-1156. https://doi.org/10.1136/bmj.39031.420637.BE

9. Dutta S, Banerjee S (2019) Rheumatic fever: a review on pathogenesis, modified diagnosis and pharmacotherapy. RRJMHS 8:4-9

10. Eroğlu AG (2016) Update on diagnosis of acute rheumatic fever : 2015 Jones criteria. Turk Pediatr Ars 51:1-7

11. Bhardwaj R, Sood A (2015) Clinical profile of acute rheumatic fever patients in a tertiary care institute in present era. J Ass Phys India 63:22-24

12. Qurashi MA (2009) The pattern of acute rheumatic fever in children: experience at the children's hospital, Riyadh, Saudi Arabia. J Saudi Hear Assoc 21(4):215-220. https://doi.org/10.1016/j.jsha.2009.10.004

13. Burke JB (1935) Erythema marginatum. Arch Dis Child 1935:359-356

14. Grover A, Dhawan A, lyengar SD, Anand IS, Wahi PL, Ganguly NK (1993) Epidemiology of rheumatic fever and rheumatic heart disease in a rural community in northern India. Bull WHO 71:59-66

15. Pratim P, Chakraborty M (2016) Erythema marginatum rheumaticum. ID Cases 4:1-2

16. Swerlick RA, Cunningham MW, Hall NK (1986) Monoclonal antibodies cross-reactive with group A streptococci and normal and psoriatic human skin. J Investig Dermatol 87(3):367-371. https://doi.org/10.1111/1523-1747.ep12524838

17. Wilson G, Dyer J, Folzenlogen D (2010) Erythema marginatum in a case of post-streptococcal arthralgia: a rash mimicking urticaria. Internet J Rheumatol 7:1-4

\section{Publisher's Note}

Springer Nature remains neutral with regard to jurisdictional claims in published maps and institutional affiliations.

\section{Submit your manuscript to a SpringerOpen ${ }^{\circ}$ journal and benefit from:}

- Convenient online submission

- Rigorous peer review

- Open access: articles freely available online

- High visibility within the field

- Retaining the copyright to your article

Submit your next manuscript at $\boldsymbol{\nabla}$ springeropen.com 